\title{
Motor Neuron Rescue in Spinal Muscular Atrophy Mice Demonstrates That Sensory-Motor Defects Are a Consequence, Not a Cause, of Motor Neuron Dysfunction
}

\author{
Rocky G. Gogliotti, ${ }^{1,2}$ Katharina A. Quinlan, ${ }^{3}$ Courtenay B. Barlow, ${ }^{1,2}$ Christopher R. Heier, ${ }^{1}$ C. J. Heckman, ${ }^{3}$ \\ and Christine J. DiDonato ${ }^{1,2}$ \\ ${ }^{1}$ Human Molecular Genetics Program, Children's Memorial Research Center, Chicago, Illinois 60614, ${ }^{2}$ Department of Pediatrics, Feinberg School of \\ Medicine, Northwestern University, Chicago, Illinois 60614, and ${ }^{3}$ Departments of Physiology, Physical Medicine and Rehabilitation, and Physical Therapy \\ and Human Movement Sciences, Feinberg School of Medicine, Northwestern University, Chicago, Illinois 60611
}

The loss of motor neurons (MNs) is a hallmark of the neuromuscular disease spinal muscular atrophy (SMA); however, it is unclear whether this phenotype autonomously originates within the MN. To address this question, we developed an inducible mouse model of severe SMA that has perinatal lethality, decreased motor function, motor unit pathology, and hyperexcitable MNs. Using an $\mathrm{Hb}$ 9-Cre allele, we increased Smn levels autonomously within MNs and demonstrate that MN rescue significantly improves all phenotypes and pathologies commonly described in SMA mice. MN rescue also corrects hyperexcitability in SMA motor neurons and prevents sensorymotor synaptic stripping. Survival in MN-rescued SMA mice is extended by only $5 \mathrm{~d}$, due in part to failed autonomic innervation of the heart. Collectively, this work demonstrates that the SMA phenotype autonomously originates in MNs and that sensory-motor synapse loss is a consequence, not a cause, of MN dysfunction.

\section{Introduction}

The survival motor neuron 1 (SMN1) gene encodes a protein that is essential for spliceosome assembly (Schrank et al., 1997; Pellizzoni et al., 1998). While complete loss of SMN is lethal to all cells, low levels of SMN cause the neuromuscular disease spinal muscular atrophy (SMA) (Lefebvre et al., 1995; Crawford and Pardo, 1996; Coovert et al., 1997; Lefebvre et al., 1997). The pathology of SMA is paradoxical because $\mathrm{SMN}$ is ubiquitously expressed in all cells, yet motor neurons (MNs) preferentially degenerate.

SMA has been modeled in several organisms to address SMN's cellular requirements. In zebrafish and Caenorhabditis elegans, restoring SMN in MNs rescues neuromuscular junction (NMJ) pathology, while in Drosophila, both MN and muscle rescue are required to correct pathology (Chang et al., 2008; Boon et al., 2009; Briese et al., 2009). Survival analysis in these models is complicated, since they rely on either maternal transcripts or temporally discordant drivers to accomplish SMN rescue.

\footnotetext{
Received Nov. 18, 2011; revised Jan. 18, 2012; accepted Jan. 25, 2012

Author contributions: R.G.G., K.A.Q., C.J.H., and C.J.D. designed research; R.G.G., K.A.Q., C.B.B., and C.R.H. performed research; R.G.G., K.A.Q., C.R.H., C.J.H., and C.J.D. analyzed data; R.G.G., K.A.Q., C.B.B., and C.J.D. wrote the paper.

This work was supported by NIH Training Grant T32 AG000260, Drug Discovery Training in Age-Related Disorders (R.G.), Families of Spinal Muscular Atrophy Grant DiD0809 (C.J.D.), and NIH NINDS Grants 1ROIN5060926 (C.J.D.), 3R01NS060926-02S3 (C.J.D.), NS034382 (C.J.H.), and NS071951 (C.J.H., K.A.Q.). K.A.Q. made use of equipment supported by NS054850. We acknowledge Herminio Cardona's and Michael Jorgensen's roles in overall colony maintenance, Carina Emery for experimental assistance, as well as the labs of Dr. Greg Cox and Dr. Robert Burgess for technical training rendered.

The authors declare no competing financial interests.

Correspondence should be addressed to Christine J. DiDonato, Children's Memorial Research Center, 2300 Children's Plaza, Box 211, Chicago, Illinois 60614. E-mail: c-didonato@northwestern.edu.

DOI:10.1523/JNEUROSCI.5775-11.2012

Copyright $\odot 2012$ the authors $\quad 0270-6474 / 12 / 323818-12 \$ 15.00 / 0$
}

Conflicting evidence exists regarding whether neuromuscular dysfunction in SMA mice originates in MNs. Gavrilina et al. (2008) demonstrated that CNS-specific SMN restoration rescued the phenotype of a severe SMA mouse model, albeit with leaky expression in skeletal muscle. Importantly, muscle specific rescue where there was no leakiness in the CNS had no survival benefit.

In contrast, mice with disease-relevant levels of SMN only within MNs and oligodendrocytes do not develop severe SMA, as one would expect from a cell-autonomous disease, but instead develop an adult form of SMA (Park et al., 2010). This suggests an additive involvement of muscle, Schwann cells, and/or peripheral factors in defining disease severity. Alternatively, these results could be due to inefficient Olig2-Cre-mediated recombination, or an unknown disease modifying role of Olig2 + oligodendrocytes (Park et al., 2010). To date, genetic experiments in mice have failed to exclusively target motor neurons, making it difficult to draw conclusions pertaining to $\mathrm{MN}$-autonomous disease mechanisms.

An important recent finding is that a loss of the central synapses, particularly the proprioceptive inputs onto MN somata and proximal dendrites, both parallels and precedes the pattern of MN loss in SMA mice (Ling et al., 2010; Park et al., 2010; Mentis et al., 2011). Mechanistically, this could indicate that defects within afferent neurons play a causative role in disease that is external to the MN (Mentis et al., 2011). If true, a simplistic interpretation would be that MNs are not affected by low Smn levels and would not benefit from autonomously increased Smn dosage; rather MNs are relatively healthy cells, whose dysfunction and loss is attributed to aberrant synaptic input.

Here, we directly address the question of MN specificity by generating a Cre-inducible mouse model of severe SMA. Using 
an $\mathrm{Hb} 9$-Cre allele, we demonstrate that $\mathrm{MN}$ rescue dramatically improves all neuromuscular phenotypes and pathologies observed in severe SMA model mice; however, survival is only extended $5 \mathrm{~d}$ due in part to failed autonomic innervation of the heart. This work demonstrates that the neuromuscular phenotype in SMA mice autonomously originates in MNs, while their lethality is multifactorial.

\section{Materials and Methods}

Ethics statement. All studies performed on mice were in accordance with the Institutional Animal Care and Use Committee regulations in place at Children's Memorial Research Center and Northwestern University's Animal Care and Use Committee guidelines, and were specifically approved under Protocols 2006-22 and 2008-03.

Animal models. Animals were kept in a controlled vivarium at $25^{\circ} \mathrm{C}$ and $50 \%$ humidity with a $12 \mathrm{~h} \mathrm{light/dark} \mathrm{photoperiod} \mathrm{and} \mathrm{monitored} \mathrm{for} \mathrm{health.}$ The official strain designations for the alleles used in this manuscript are as follows: SMN2, FVB.Cg-Tg(SMN2)89Ahmb Smn ${ }^{\text {tm1Msd }}$; Smn ${ }^{2 B-N e o}$, B6.127Smn1 $1^{\text {tm1Cdid }}$; Smn ${ }^{2 B}, \quad$ B6.127-Smn1 $1^{\text {tm1.1Cdid } ; \quad H b 9-C r e, ~ B 6 ; 129 S-~}$ $H l x b 9^{\text {tm4 (cre)Tmj }}$; ZGFP, B6.Cg-Tg(ACTB-Bgeo/GFP)21 Lbe (Arber et al., 1999; Monani et al., 2000; Novak et al., 2000; Hammond et al., 2010). The official name for the severe inducible model reported here [(SMN2)89Ahmb $\left.{ }^{+/-}, \mathrm{Smn}^{2 B-N e o / 2 B-N e o}\right]$ is $\mathrm{Tg}(\mathrm{SMN} 2) 89 \mathrm{Ahmb} / \mathrm{J}$, Smn $1^{\text {tmlCdid/ tmlCdid. }}$.

Severe inducible SMA pups were generated by crossing a breeder stock of $\mathrm{SMN}^{+/+} ; \mathrm{Smn}^{2 \mathrm{~B}-\mathrm{Neo} /+} \mathrm{SMA}$ mice with a $\mathrm{Smn}^{2 \mathrm{~B}-\mathrm{Neo} /+}$ mouse to create $S M N 2^{+/-} ; S_{m}{ }^{2 B-N e o / 2 B-N e o}$ SMA pups. For MN-rescue experiments, an $\mathrm{Hb} 9-\mathrm{Cre}{ }^{+/-}$mouse was intercrossed with a $\mathrm{Smn} n^{2 B-N e o /+}$ heterozygote. F1 progeny that were positive for both the $S m n^{2 B-N e o}$ and the $\mathrm{Hb} 9-\mathrm{Cre}$ alleles were backcrossed to the $S M N 2^{+/-} ; S_{m} n^{2 B-N e o /+}$ breeder stock to create SMA mice containing both with (MN-rescued SMA) and without (severe inducible SMA) $\mathrm{Hb}$ 9-Cre. In all of the described experiments, both male and female pups were used in proportions approximated to be equal.

Genotyping. The presence of the neomycin cassette was verified via PCR using a forward primer within neomycin ( $5^{\prime}$-gcattaaagcttggctggac) and a reverse primer in Smn intron 7 (5' -gagaccgaggcaggctaac) that amplifies a neomycin specific band of $353 \mathrm{bp}\left(\mathrm{Smn} n^{2 \mathrm{~B}-\mathrm{Neo}}\right)$. The addition of a third primer within intron 6 (5'-tcccaggcagttttagactca) allows for the detection of a WT band of 750bp $\left(\mathrm{Smn}^{+}\right)$. When the neomycin cassette has been removed by Cre-recombinase, a third $850 \mathrm{bp}$ band corresponds to the excised allele $\left(\mathrm{Smn}^{2 B}\right)$. The presence of the $\mathrm{Hb}$ - -Cre allele was detected using generic Cre primers (forward, $5^{\prime}$-atgtccaatttactgaccg; reverse, $5^{\prime}$-cgccgcataaccagtgaaac). Assessment of the (SMN2) $89 \mathrm{Ahmb}$ allele was conducted as described previously (Gavrilina et al., 2008).

Phenotyping. In all phenotypic assays, the researcher recording the score was blinded to the genotype of the litter being assessed. Tube test was conducted as described by Heier et al. (2010a). Righting reflex was monitored on odd days beginning at postnatal day 3 (P3) and defined as the time taken to turn over and place all four paws simultaneously on a hard benchtop after being placed in supine position. If righting did not occur in, 1 min the test was scored as a failure. Electrocardiography (ECG) was conducted as described by Heier et al. (2010b). The end stage was defined as 2 consecutive days of weight loss and an inability to right within $60 \mathrm{~s}$ in cage bedding.

Western blot analysis. To quantify Smn levels, $5 \mu \mathrm{g}$ of total protein per tissue was resolved on a NuPage Novex $4-12 \%$ Bis-Tris gel and transferred to nitrocellulose membrane. Smn was detected by Western blot using the Li-COR Odyssey system as described previously (Hammond et al., 2010).

Immunofluorescence. NMJ staining was performed on whole-mount intercostals (ICs) and triangularis sterni (TS) using a combination of neurofilament [1:100; 2H3; Developmental Hybridoma Bank (DHB)], synaptic vesicle 2 (SV2; $1: 10 ; \mathrm{DHB})$, and rhodamine conjugated $\alpha$-bungarotoxin ( $\alpha$ BTX; 1:250; Invitrogen). Briefly, whole-mount tissues were dissected and fixed in $2 \%$ paraformaldehyde overnight at $4^{\circ} \mathrm{C}$. The following day, they were washed in PBS for $2 \mathrm{~h}$ at room temperature (RT). Primary antibodies (NF and SV2) were then added in blocking buffer ( $5 \%$ bovine serum, $2 \%$ Triton X-100, 0.5\% glycine in PBT). Samples were incubated in primary for $48-72 \mathrm{~h}$ at RT on a rocker, washed three times for 10 min each in PBS, and incubated in secondary antibody (1:250, GAM-488 and 594- $\alpha$ BTX) for $24 \mathrm{~h}$ at RT. Samples were again washed three times for 10 min each in PBS and mounted on slides with Clear Mount mounting media (Invitrogen).

For MN staining, spinal cords were dissected, fixed in $2 \%$ PFA at $4^{\circ} \mathrm{C}$ overnight, cryoprotected in 30\% sucrose for 12-24 h, and embedded in OCT. Serial sections (12 $\mu \mathrm{m}$ thick) were collected, and to avoid repeat counts, every 15th section (180 $\mu \mathrm{m}$ apart) was used to quantify MN number. Before ChAT and Islet-1/2 staining, one slide per series was stained with fluorescent Nissl $(0.5 \mathrm{mg} / \mathrm{ml}$ cresyl violet $)$ to assist in determining the exact location within the spinal cord. Following antigen retrieval, equivalent sections from an adjacent slide were stained in 5\% donkey serum for ChAT (Millipore Bioscience Research Reagents; 1:100) and Islet-1/2 (DHB; 4D5, 1:100 plus 2H3, 1:100). Only double-positive cells localized in the ventral horn were classified as MNs. Tyrosine hydroxylase (TH), vesicular glutamate transporter 1 (vGlut1), and Smn staining, as well as Smn gem counts were conducted as described previously (DiDonato et al., 2003; Heier et al., 2010a; Ling et al., 2010; Park et al., 2010; Le et al., 2011).

NMJ innervation/maturity quantification. All NMJs were imaged whole mount on a Leica spinning disc confocal microscope using Slidebook software. $Z$ stacks were deconvolved in Slidebook, and the projection image was used for final analysis. Images were de-identified and randomized before quantification for blinding purposes. Blinded images were assessed for innervation and maturity using Adobe Photoshop, CS4 extended edition. Innervation status was defined visually as fully innervated $(>80 \%)$, partially innervated $(15-80 \%)$, or denervated $(\leq 15 \%)$. Postsynaptic maturity was defined as junctions containing homogeneous plaques, folds, perforations, or secondary structure. Only after quantification was complete were the images reidentified for statistical analysis.

Electrophysiology. Mice at P4-P5 were deeply anesthetized with isofluorane, decapitated, and eviscerated. The spinal cord was quickly removed and embedded in $2.5 \% \mathrm{w} / \mathrm{v}$ agar, and super glued to a stainless-steel platform, and $350 \mu \mathrm{m}$ transverse slices were made using a Leica 1000 vibratome as described previously (Quinlan et al., 2011). During both spinal cord isolation and slicing, the spinal cord was immersed in $1-4^{\circ} \mathrm{C}$ high-osmolarity dissecting solution containing the following (in mM): 234 sucrose, $2.5 \mathrm{KCl}, 0.1 \mathrm{CaCl}_{2} \cdot 2 \mathrm{H}_{2} \mathrm{O}, 4 \mathrm{MgSO}_{4}$. $7 \mathrm{H}_{2} \mathrm{O}, 15 \mathrm{HEPES}, 11$ glucose, and $1 \mathrm{Na}_{2} \mathrm{PO}_{4}, \mathrm{pH} 7.4$ when bubbled with $95 \% \mathrm{O}_{2} / 5 \% \mathrm{CO}_{2}$. After cutting, the slices were incubated for $>1 \mathrm{~h}$ at $30^{\circ} \mathrm{C}$ in incubating solution containing the following (in $\mathrm{mM}$ ): $126 \mathrm{NaCl}, 2.5$ $\mathrm{KCl}, 2 \mathrm{CaCl}_{2} \cdot 2 \mathrm{H}_{2} \mathrm{O}, 2 \mathrm{MgCl}_{2} \cdot 6 \mathrm{H}_{2} \mathrm{O}, 26 \mathrm{NaHCO}_{3}$, and 10 glucose, $\mathrm{pH}$ 7.4 when bubbled with $95 \% \mathrm{O}_{2} / 5 \% \mathrm{CO}_{2}$. During recording, slices were perfused at a rate of $2.5-3.0 \mathrm{ml} / \mathrm{min}$ with a modified Ringer's solution containing the following (in mM): $111 \mathrm{NaCl}, 3.09 \mathrm{KCl}, 25 \mathrm{NaHCO}_{3}, 1.10$ $\mathrm{KH}_{2} \mathrm{PO}_{4}, 1.26 \mathrm{MgSO}_{4}, 2.52 \mathrm{CaCl}_{2}$, and 11.1 glucose. Whole-cell patchclamp recording was performed using 1-4 $\mathrm{M} \Omega$ glass electrodes containing the following (in mM): 150 Texan red dextran (3000 molecular weight; Invitrogen), $138 \mathrm{~K}$-gluconate, $10 \mathrm{HEPES}, 5 \mathrm{ATP}-\mathrm{Mg}$, and 0.3 GTP-Li (all from Sigma). Electrodes were positioned using a Sutter Instrument MP-285 motorized micromanipulator. Whole-cell patchclamp measurements were performed at room temperature using the Multiclamp 700B amplifier (Molecular Devices).

Only neurons maintaining a resting potential of $-50 \mathrm{mV}$ or lower, an action potential height of $>0 \mathrm{mV}$, a series resistance of $\leq 25 \mathrm{M} \Omega$, and an input resistance of $\leq 200 \mathrm{M} \Omega$ were included in this study. Recordings were performed in current- and voltage-clamp modes [more details available in the study by Quinlan et al. (2011)]. In voltage-clamp mode, holding potential was set to $-90 \mathrm{mV}$, and neurons were subjected to a slow, depolarizing voltage ramp of $12 \mathrm{mV} / \mathrm{s}$, bringing the cell to $+6 \mathrm{mV}$ in $8 \mathrm{~s}$, and then back to the holding potential in the following $8 \mathrm{~s}$. Persistent inward current (PIC) amplitudes were measured from leaksubtracted current traces. In current-clamp mode, depolarizing ramps were used for testing $I_{\mathrm{ON}}$ (the current level at firing onset), $I_{\mathrm{OFF}}$ (the current level at cessation of firing), and the frequency-current relationship. Characteristics of the action potential, including overshoot (past $0 \mathrm{mV}$ ), duration at half peak, and rate of rise were measured from the 
A

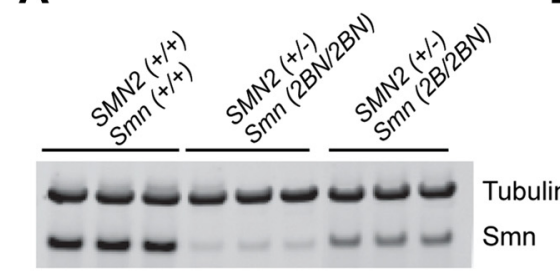

P5

Spinal Cord

D

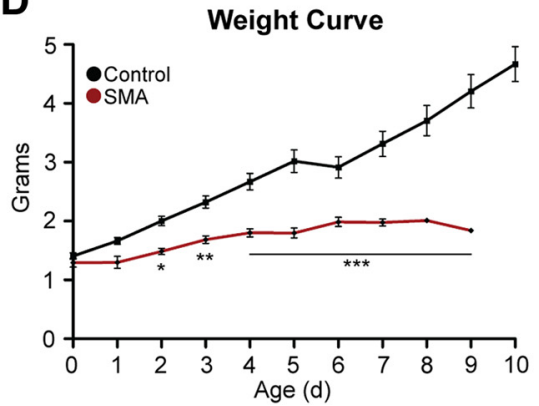

B

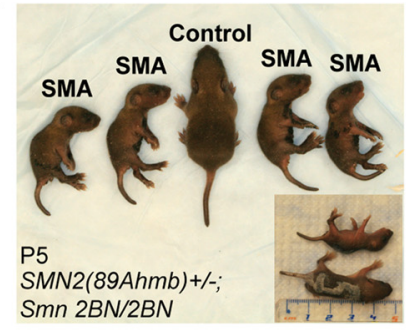

E

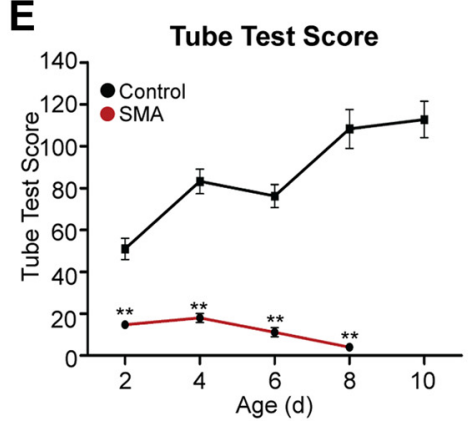

C Survival Curve

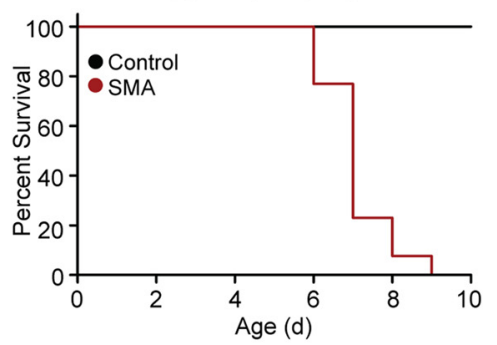

$\mathbf{F}$

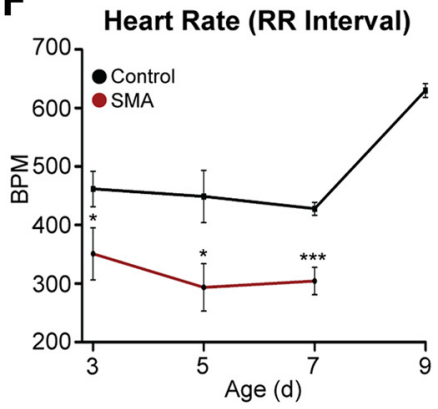

Figure 1. Phenotypic characterization of severe inducible SMA mice. $A$, Western blot analysis of Smn levels. The homozygous presence of the neomycin cassette decreases $S \mathrm{mn}$ to $6 \%$ relative to littermate controls. This level is increased to an asymptomatic $37 \%$ if one neomycin-containing allele is replaced with a rescued allele. $\boldsymbol{B}$, Photomicrograph. Severe inducible SMA mice were smaller and weaker in appearance than littermate controls and exhibited near complete paralysis by P5. The ruler is in centimeters. $C$, Kaplan-Meier survival curve. Median survival of severe inducible SMA mice is $7 \mathrm{~d}$ (control, $n>50 ; S M A, n=15 ; p \leq 0.001$, log-rank test). D, SMA mice weighed significantly less than controls (P2 or later; $p \leq 0.05$ ) and generally died after 2 consecutive days of weight loss (control, $n=16 ;$ SMA, $n=14 ; 2$-way ANOVA, Bonferroni's post-test). $\boldsymbol{E}$, Tube test scores in severe SMA mice were significantly diminished from the earliest detectable points (P2 or later; $p \leq$ 0.01; 1-way ANOVA, Bonferroni's post-test; control, $n=22 ; \mathrm{SMA}, n=15$ ). $F$, SMA mice were bradycardic from the earliest point analyzed by ECG (P3; $p \leq 0.04 ;$ Student's $t$ test; control, $n=10$; SMA, $n=7)$. Values are shown as mean \pm SEM. ${ }^{*} p \leq 0.05 ;{ }^{* *} p \leq 0.01 ;{ }^{* * *} p \leq 0.001$.

first spike elicited from the current ramp. Threshold voltage was determined as the voltage at which the rate of rise of the membrane potential exceeded $10 \mathrm{mV} / \mathrm{ms}$, indicating the beginning of the spike. Synaptic potentials were quantified as the number of sharp deflections in membrane potential (either depolarizing or hyperpolarizing) occurring over 5-10 s. Data was collected on Winfluor software (University of Strathclyde, Glasgow, Scotland) and analyzed using Spike2 software (Cambridge Electronic Design). $Z$ stacks were obtained using a Bio-Rad 2100 MPD laser scanning microscope. The Coherent Chameleon Ultra II laser was used at $920 \mathrm{~nm}$. Bio-Rad LaserSharp software was used to collect $1024 \times 1024$ pixel $Z$ stacks, up to $200 \mu \mathrm{m}$ depth, in $1.0 \mu \mathrm{m}$ steps, and using a Kalman 4 filter. Image analysis was performed using ImageJ (NIH).

Statistical analysis. Statistical analysis was analyzed using Graph Pad Prism software (version 4.0) and Microsoft Excel. Kaplan-Meier survival curves were compared using log-rank tests. Significance in weights, tube test scores, innervation status, and postsynaptic maturity was determined using either a one- or two-way ANOVA with a Bonferroni post hoc comparison or Student's $t$ test as appropriate. Significance pertaining to $\mathrm{MN}$ counts and heart rate was analyzed with a Student's $t$ test.

\section{Results}

\section{Smn inducible model of severe SMA}

Smn inducible SMA mice were generated by breeding the $S m n 1^{t m 1 \text { Cdid }}$ allele (hereafter referred to as $S m n^{2 B-N e o}$ ) with the commonly used $\mathrm{Tg}(\mathrm{SMN} 2) 89 \mathrm{Ahmb}$ allele (hereafter referred to as SMN2) (Monani et al., 2000; Hammond et al., 2010). Smn $n^{2 B-N e o / 2 B-N e o ~}$ embryos die by E9 due to low Smn protein levels (1-3\%), but Smn dosage can be dramatically increased if the floxed neomycin cassette is removed by Cre-recombinase [discussed extensively in the study by Hammond et al. (2010)]. By breeding one copy of the SMN2 transgene to a $S m n^{2 B-N e o / 2 B-N e o}$ background $\left(S M N 2^{+/-} ; S m n^{2 B-N e o / 2 B-N e o}\right)$, we increased Smn levels to $6 \%$ relative to $S M N 2^{+/+} ; \mathrm{Smn}^{+/+}$controls (Fig. $1 A$ ). Importantly, this rescued the lethality observed in $S m n^{2 B-N e o / 2 B-N e o}$ embryos and allowed for postnatal survival.

Severe inducible SMA mice have a neuromuscular phenotype $S M N 2^{+/-} ; S_{m n}{ }^{2 B-N e o / 2 B-N e o}$ (hereafter referred to as severe inducible SMA) pups exhibited phenotypes similar to established severe models of SMA, including reduced survival (median survival, $7 \mathrm{~d} ; p=0.001$ ), reduced weight (P2 or later; $p \leq 0.05$ ), and diminished motor function (as quantified by tube test; P2 or later; $p \leq 0.01$ ) (Fig. $1 B-E$ ) (Hsieh-Li et al., 2000; Monani et al., 2000; Le et al., 2005). Severe inducible SMA pups had near complete paralysis by P5 and never developed the ability to right when placed on their back. To assess overall health, we used electrocardiography (ECG) and found that severe inducible SMA mouse heart rates were significantly bradycardic from the earliest time point assayed (P3, SMA, $351 \pm 95 \mathrm{bpm}$ vs control, $462 \pm 118$ bpm; $p=0.04$ ) and declined thereafter (Fig. $1 F$ ).

To confirm that the minimal level of excision (one allele per cell) would increase Smn to asymptomatic levels, we used breeding to replace one of the inducible alleles $\left(S m n^{2 B-N e o}\right)$ with a $S m n 1^{\text {tml.1Cdid }}$ allele (referred to hereafter as $S m n^{2 B}$ ) that had already been induced by a E2A germline Cre. Western blot analysis confirmed $S M N 2^{+/-}$; $S m n^{2 B / 2 B-N e o}$ pups had significantly increased Smn levels from 6 to 37\% in P5 spinal cord (Fig. 1A). Importantly, this whole body rescue approach resulted in mice that survived over one year and were phenotypically indistinguishable from control littermates (data not shown). These experiments demonstrate that neomycin excision in even one of the two alleles is enough to correct the severe SMA-like phenotype documented in this model. 

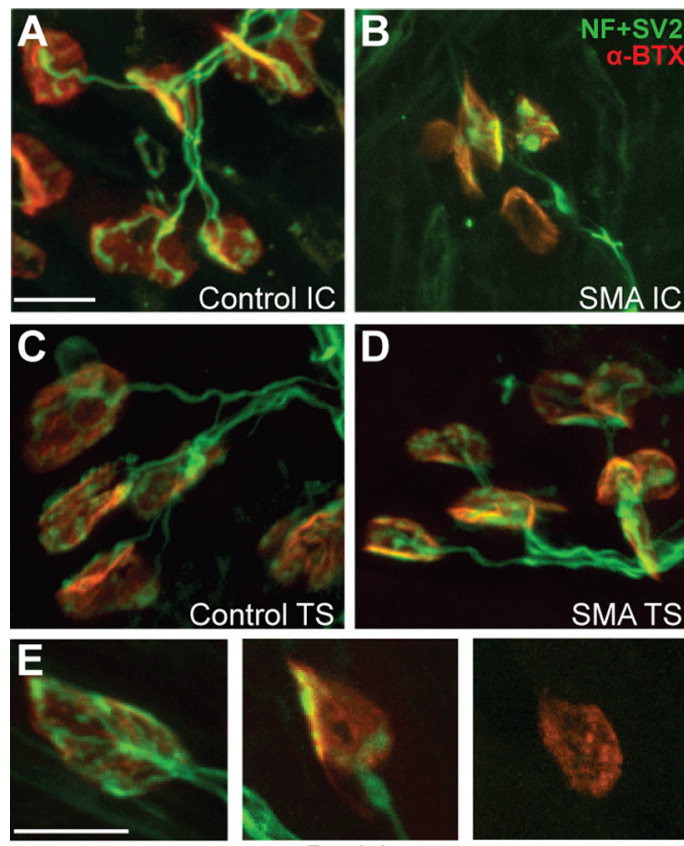

Partial Innervation

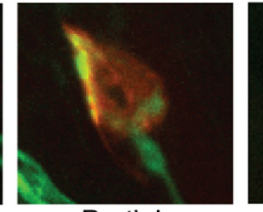

Full Innervation

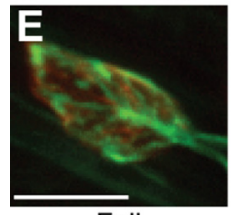

H

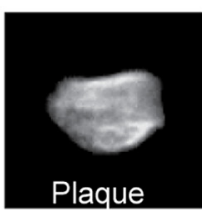

I
IC Motor Endplate Maturity

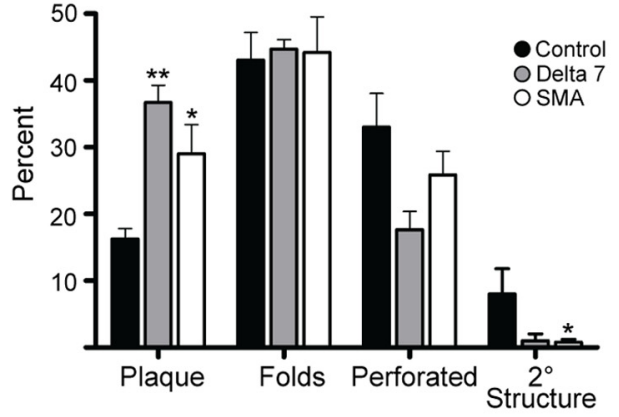

K

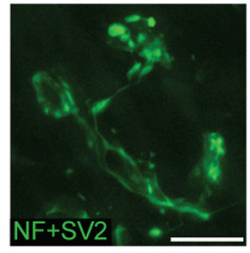

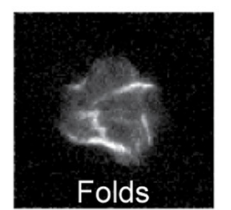

Folds

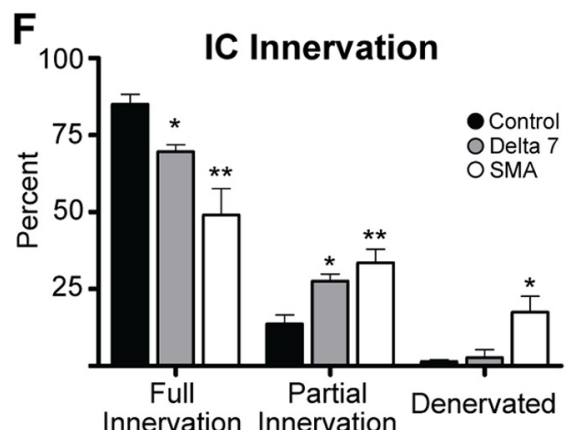

G

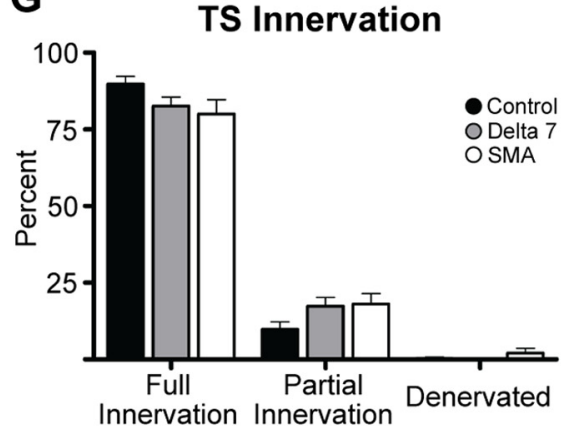

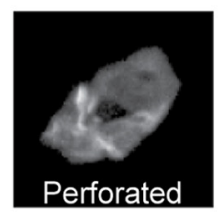

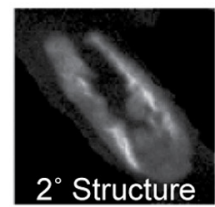

$J$

TS Motor Endplate Maturity

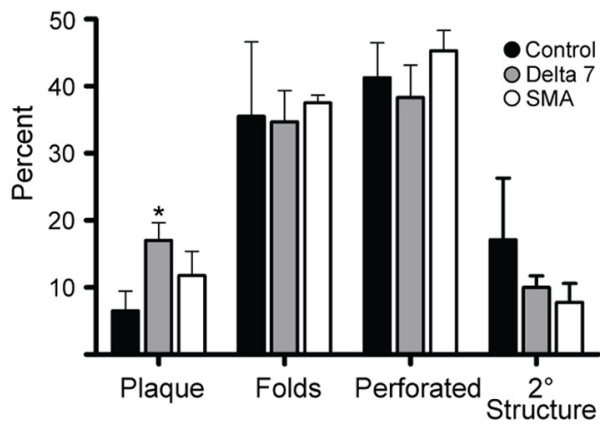

L

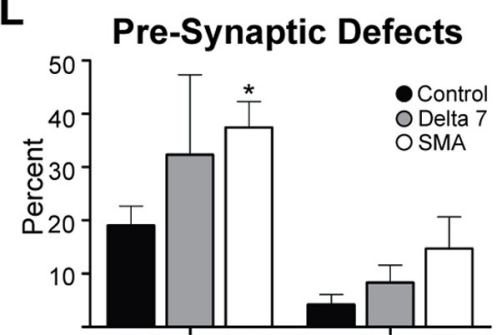

Figure 2. Severe inducible SMA mice have presynaptic and postsynaptic defects. $\boldsymbol{A}-\boldsymbol{D}$, Micrograph images depicting control $(\boldsymbol{A}, \boldsymbol{C})$ and mutant $(\boldsymbol{B}, \boldsymbol{D})$ IC and TS NMJs, respectively. $\boldsymbol{E}$, Representative images of NMJs that have full innervation, have partial innervation, or are denervated. $\boldsymbol{F}$, Severe inducible $(n=7)$ and delta-7 SMA mice $(n=3)$ had a decrease in the number of fully occupied motor endplates in the ICS $(p=0.007$ and $p=0.02$, respectively; 2 -way ANOVA, Bonferroni's post-test). $\mathbf{G}$, Severe inducible and delta-7 SMA mice showed no defects in innervation of the TS. $\boldsymbol{H}$, Examples of postsynaptic maturity. $\boldsymbol{I}, \boldsymbol{J}$, Severe inducible $(n=7)$ and delta-7 SMA mice $(n=3)$ had immature motor endplates in the ICs and protection in the TS $(n=5$, control). $\boldsymbol{K}, \boldsymbol{L}$, Severe inducible $(n=7)$ and delta-7 SMA mice $(n=3)$ had NF accumulation in the ICs and exhibited resistance to disease in the TS $(n=5$, control). Greater than 50 motor endplates per biological replicate were assessed for innervation, postsynaptic maturity, and presynaptic defects. Scale bars: $50 \mu \mathrm{m}$. Graph values are shown as mean \pm SEM. ${ }^{*} p \leq 0.05 ;{ }^{* *} p \leq 0.01$. 
Presynaptic and postsynaptic defects in severe inducible SMA mice

To determine the extent of motor unit pathology in end-stage (P6) severe inducible SMA mice, we examined the fast-synapsing intercostal (IC) and the delayed synapsing triangularis sterni (TS) muscles. These muscles were chosen due to their role in maintaining proper respiratory function, one of the most critical deficits in human SMA patients.

The ICs of severe inducible SMA mice had a significant decrease in the number of fully innervated motor endplates $(-36 \pm 9 \% ; p=$ 0.007 ) (Fig. $2 A, B, E, F)$. This correlated with significant increases in both the number of partially occupied and denervated endplates. In contrast, TS NMJs were largely protected and did not significantly differ from controls (Fig. $2 C-E, G)$. Hence, in this SMA model and time point, we consider the IC to be a vulnerable muscle and the TS to be a resistant muscle (McGovern et al., 2008; Ling et al., 2010).

Additionally, we assessed the postsynaptic architecture of $\alpha \mathrm{BTX}$-stained motor endplates, which are known to have delayed maturation in SMA mice (Murray et al., 2008; Kong et al., 2009). Relative to control littermates, severe inducible SMA pups had a $13 \pm$ $4 \%(p=0.05)$ increase in IC homogeneous motor endplates, and a $7 \pm 0 \%(p=0.04)$ decrease in the number of endplates containing secondary structure (Fig. $2 \mathrm{H}, \mathrm{I}$ ). Consistent with the innervation results, a similar pattern of protection was observed in the TS (Fig. $2 J$ ).

Finally, we quantified two classic presynaptic hallmarks of neurodegeneration: neurofilament accumulation and delayed/failed axonal pruning (Fig. $2 H$ ). We observed an $18 \pm 5 \%$ $(p=0.03)$ increase in these presynaptic defects in SMA motor axons within the ICs, while SMA motor axons in the TS did not significantly differ from controls (Fig. 2I).

To place the pathology of our model in context with a commonly used model of SMA, we included the delta-7 mouse in our analysis (Le et al., 2005). Consistent with the milder phenotype at P6, the decrease in fully occupied NMJs $(-15 \pm 2 \% ; p=0.02)$ and the increase in partially occupied NMJs $(+20 \pm 4 \% ; p=0.02)$ within the ICs were all less dramatic in delta-7 mice relative to severe inducible SMA mice. Delta-7 and severe inducible SMA mice also demonstrated a parallel pattern of delayed motor endplate maturation and presynaptic defects (Fig. 2 K,L) (Murray et al., 2008; Kong et al., 2009).

\section{$\mathrm{Hb9-Cre-driven} \mathrm{recombination} \mathrm{increases} \mathrm{Smn}$ expression in spinal MNs}

The exact role of MNs in SMA remains an enigmatic mechanistic question. To address this point using severe inducible SMA mice, we used a Cre allele driven by the $\mathrm{Hb} 9$ promoter (Jax strain 6600) (Arber et al., 1999). In this widely used allele, Cre becomes active in all MNs and in a rare population of interneuron progenitors at embryonic day 9.5 (E9.5). It is of note that the prion promoter
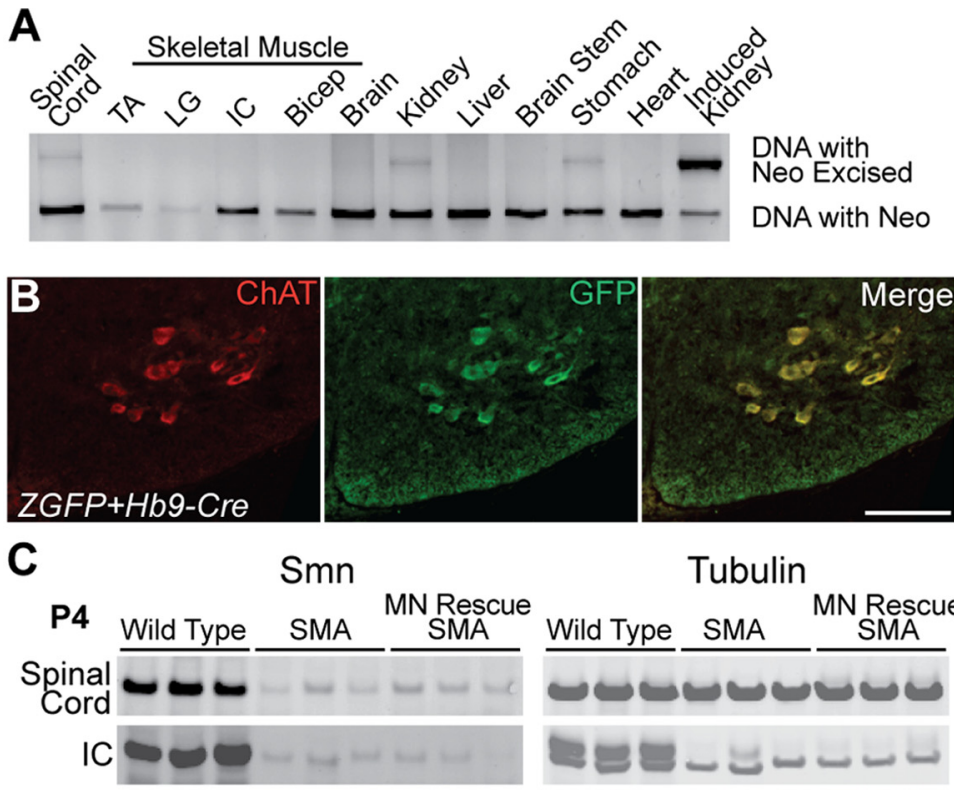

Tubulin

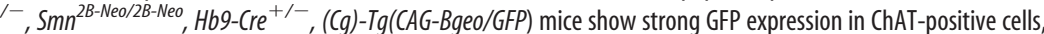

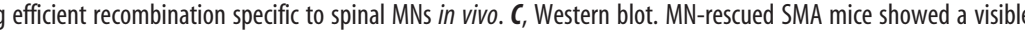
demonstrated a significant increase in the number of MNs containing nuclear gems (SMA, $17 \pm 3 \%$ vs MN-rescued SMA, $51 \pm$ $2 \% ; p=0.003)$, as well as the average number of gems per MN, confirming that Smn dosage was increased in MNs. White arrows denote gems (Table 1). Scale bars: $B, 50 \mu \mathrm{m} ; D, 100 \mu \mathrm{m}$.

used in previous murine rescue experiments had a comparable temporal expression pattern, with expression being detected at E7.5 (Tremblay et al., 2007). Hb9-Cre is notably absent in a small percentage of lumbar MNs in the lateral motor column (LMC), but has robust expression in the cervical and thoracic spinal cord (Kramer et al., 2006). Importantly, it is not expressed in skeletal muscle, although minor amounts of excision were observed in kidney and stomach via PCR analysis (Fig. 3A). P5 mice doubly transgenic for $\mathrm{Hb}$ 9-Cre and a ZGFP reporter allele were used to verify MN specificity, as only ChAT-positive MNs stained positive for GFP (with the rare exception of the $H b 9$ interneurons) (Fig. 3B) (Novak et al., 2000; Kramer et al., 2006).

We next bred the Hb9-Cre allele onto our severe inducible SMA background (hereafter referred to as MN-rescued SMA) and analyzed Smn levels in a variety of tissues via Western blot. In agreement with the expression pattern of $\mathrm{Hb}$ - $\mathrm{Cre}$, Smn levels increased slightly in the spinal cord (a dramatic increase would not be expected given the relatively small cellular contribution of 
Table 1. Spinal motor neuron gem counts

\begin{tabular}{|c|c|c|c|c|c|c|c|c|c|c|}
\hline \multirow[b]{2}{*}{ Group ID } & \multirow[b]{2}{*}{ Genotype } & \multirow{2}{*}{$\begin{array}{l}\text { Avg. gems } \\
\text { per cell }\end{array}$} & \multirow{2}{*}{$\begin{array}{l}\text { MNs } \\
\text { counted }\end{array}$} & \multirow{2}{*}{$\begin{array}{l}\text { MNs with } \\
\text { gems }\end{array}$} & \multirow{2}{*}{$\begin{array}{l}\% \text { MNs } \\
\text { with gems }\end{array}$} & \multicolumn{4}{|c|}{ Number of cells with } & \multirow[b]{2}{*}{$N$} \\
\hline & & & & & & 0 Gems & $1 \mathrm{Gem}$ & 2 Gems & 3 Gems & \\
\hline Control & $\mathrm{SMN2} 2^{+/-} \mathrm{Smn}^{2 \mathrm{~B}-\mathrm{NeO} /+}$ & $1.07 \pm 0.19$ & 155 & 106 & $68 \pm 5 \%$ & 49 & 61 & 29 & 16 & 3 \\
\hline SMA & $\mathrm{SMN} 2^{+/-}, \mathrm{Smn}^{2 B-\mathrm{Neo} / 2 \mathrm{~B}-\mathrm{Neo}}$ & $0.19 \pm 0.02^{* *}$ & 149 & 26 & $17 \pm 3 \%$ & 123 & 24 & 2 & 0 & 3 \\
\hline Motor Neuron Rescue SMA & $\mathrm{SMN2}^{+/-}, \mathrm{Smn}^{2 \mathrm{~B}-\mathrm{Neo} / 2 \mathrm{~B}-\mathrm{Neo}}, \mathrm{Hb} 9-\mathrm{Cre}^{+/-}$ & $0.63 \pm 0.11^{\dagger}$ & 250 & 122 & $51 \pm 2 \%$ & 128 & 99 & 13 & 10 & 5 \\
\hline
\end{tabular}

Table values are mean $\pm S E M{ }^{* *} p \leq 0.01$ relative to control; ${ }^{\dagger} p \leq 0.05$ relative to severe inducible SMA. $N=$ number of biological replicates. One-way ANOVA with Bonferroni's post hoc analysis.

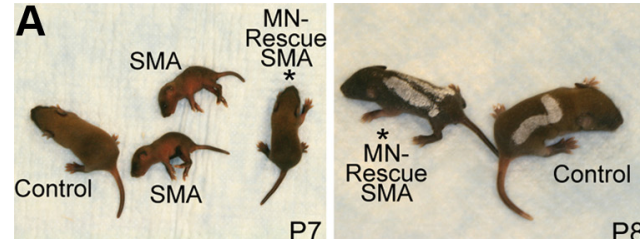

B
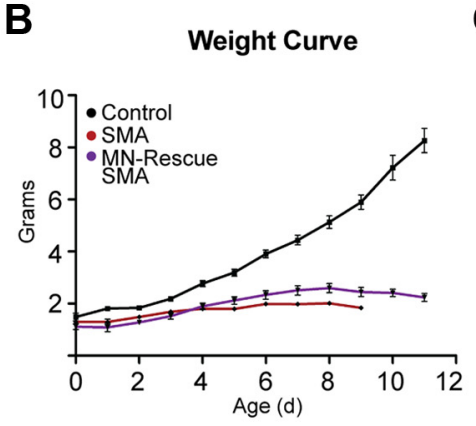

D

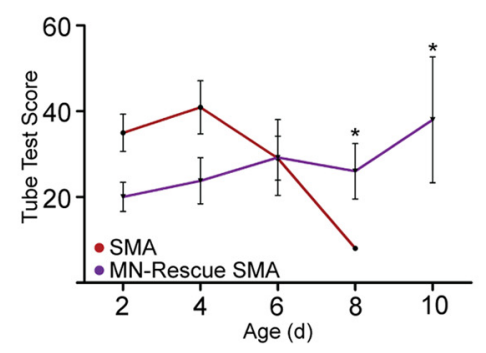

E

C
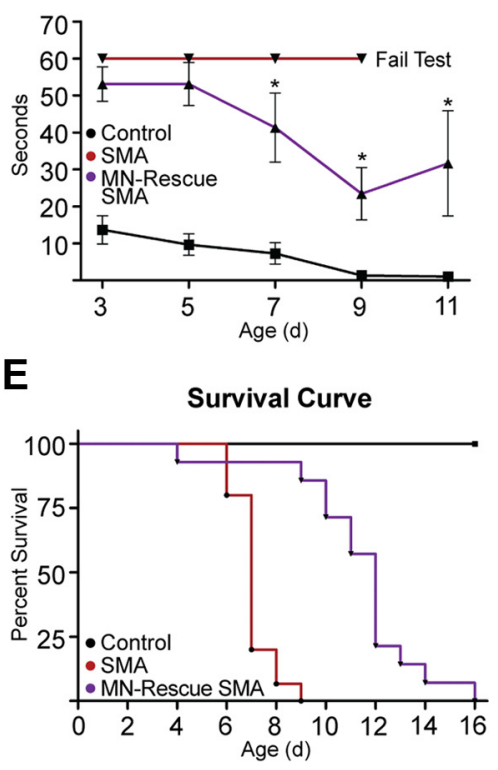

Figure 4. MN-rescued SMA mice have improved motor function, but minimally improved survival. $\boldsymbol{A}$, Gross phenotype of severe inducible SMA mice is improved by $\mathrm{Hb}$-Cre. Pups are numbered using a white paint pen. $\boldsymbol{B}$, Despite improved motor function, MN-rescued SMA mice were runted and did not show significantly improved weights (control, $n>50 ;$ SMA, $n=13$; MN-rescued SMA, $n=10$ ). C, $\boldsymbol{D}$, MN-rescued SMA mice demonstrated a decreased level of consciousness (lethargy) early in life, resulting in poor motor function scores. This phenotype dissipates between $\mathrm{P} 6$ and $\mathrm{P} 8$, and righting reflex and tube test scores significantly improved ( $p \leq 0.05$ and $p \leq 0.05$, respectively; 2-way ANOVA, Bonferroni's post-test; control, $n \geq 21$; $\mathrm{SMA}, n=9 ;$ MN-rescued SMA, $n=7)$. $\boldsymbol{E}$, Kaplan-Meier survival curve. Despite the dramatic improvement in motor function, median survival was only increased $5 \mathrm{~d}$ in MN-rescued SMA mice ( $p \leq 0.001$, log-rank test) (control, $n>50 ;$ SMA, $n=13$; MN-rescued SMA, $n=12$ ). Values are shown as mean \pm SEM. ${ }^{*} p \leq 0.05$.

MNs) (Fig. 3C). Importantly, there was no increase in Smn levels in the skeletal muscle, kidneys, or brain. To confirm Smn was increased in SMA motor neurons, we quantified nuclear gems, and found a significant increase in the average number of gems per MN in MN-rescued SMA mice ( $0.63 \pm 0.11$ gems; $p \leq 0.05)$ relative to severe inducible SMA mice $(0.19 \pm 0.02$ gems) (Table 1). These results demonstrate that $\mathrm{Hb} 9$-Cre significantly increases Smn levels in MNs, while leaving peripheral tissues with SMA relevant Smn protein dosage.

\section{Hb9-Cre significantly improves phenotype, but minimally improves survival}

Having validated that $\mathrm{Hb}$ 9-Cre was increasing Smn dosage exclusively in MNs, we assessed the phenotype of MN-rescued SMA mice.
MN rescue dramatically improved the appearance and motor function of severe inducible SMA mice. While still runted, MN-rescued SMA pups had significantly improved righting reflex times $(\mathrm{P} 7-\mathrm{P} 11 ; p \leq 0.01)$ and were ambulatory throughout their entire life, a feature not seen in other severe SMA models (Fig. 4A$C)$. MN-rescued SMA mice also had significantly improved tube test scores (P8-P10; $p \leq$ 0.05 ) that improved steadily with age (Fig. 4D). Strangely, MN-rescued SMA mice exhibited a decreased level of consciousness or lethargy early in life that was not observed in severe inducible SMA mice or in control littermates, with or without $\mathrm{Hb} 9$-Cre. In these instances, MN-rescued SMA mice refused to attempt the righting reflex and tube tests, despite having the functional ability to successfully complete each test. The pups outgrew this passive behavior after P6; however, its presence resulted in poor motor function scores early in life (Fig. 4C,D).

Despite the improved motor function, median survival of MN-rescued SMA mice increased by only $5 \mathrm{~d}(p=0.001)$ (Fig. $4 E$ ). At the end stage, MN-rescued SMA mice were ambulatory and did not have significant paralysis, demonstrating only lateral instability of their hind limbs. This is likely attributed to a loss of MNs within the lumbar LMC, which control muscles responsible for stability and demonstrate weak $\mathrm{Hb} 9$-Cre expression (discussed further in next section).

\section{MN rescue improves SMA motor unit pathology}

To determine whether $\mathrm{MN}$ rescue corrected the presynaptic and postsynaptic motor unit pathology observed in severe inducible SMA pups, we examined NMJs in the ICs and TS of control and end-stage MN-rescued SMA mutants (the end stage was phenotypically defined as 2 consecutive days of weight loss). After blinded quantification, analysis revealed no significant differences in innervation status, endplate maturity, or presynaptic defects in the ICs of control and MN-rescued SMA mice (Fig. 5A-C) (data not shown). The TS also had no difference in innervation status and demonstrated only a significant decrease in junctions containing secondary structure $(-34 \pm 6 \% ; p=0.04)$ (Fig. 5D,E).

To discount the possibility that MNs outside of those that innervate the TS and ICs were affected by disease, we quantified ChAT and Islet-1/2 double-positive MNs in the cervical, thoracic, and lumbar spinal cords of control, severe inducible, and MNrescued SMA pups at end stage (Fig. $3 F$ ). In severe inducible SMA mice, a significant loss in average MNs per ventral horn of $4.4 \pm$ 
$0.2,4.1 \pm 0.3$, and $4.6 \pm 1.3$ was observed in cervical, thoracic, and lumbar spinal cords $(p=0.01, p=0.04$, and $p=0.05)$, respectively (Fig. $5 G$ ). In contrast, MN-rescued SMA spinal cords did not differ significantly from controls in the cervical and thoracic regions. A significant $5 \pm 1 \mathrm{MN}$ decrease was observed in L3-L5 spinal cord sections $(p=$ 0.03 ) (Fig. $5 G$ ). This was not unanticipated, as the Hb9-Cre allele used here is known to have incomplete expression in the lumbar LMC (Kramer et al., 2006). A blinded postanalysis confirmed that the LMC in MNrescued SMA mice presented with a $25 \pm 9 \%$ reduction in MNs per ventral horn $(p=$ 0.04), while the medial motor column (MMC) showed no significant decrease (Fig. $5 H, I)$. These results support the conclusion that $\mathrm{MN}$ rescue is sufficient to prevent the neuromuscular pathology in our SMA model mice, since only MNs that appeared to be lost were those known to lack Hb9-Cre expression.

\section{$\mathrm{Hb9-Cre} \mathrm{rescues} \mathrm{loss} \mathrm{of}$} sensory-motor synapses

To determine the effect of $\mathrm{MN}$ rescue on glutamatergic excitatory synapses, which are known to be lost in delta-7 SMA mice, we quantified vGlut1-positive puncta juxtaposed to ChAT-positive MNs (Ling et al., 2010; Park et al., 2010; Mentis et al., 2011). End-stage (P5) severe inducible SMA mice had a significant reduction in the number of vGlut1-positive synapses per $100 \mu \mathrm{m}$ perimeter when compared to control littermates (control, $3.67 \pm 0.32$ vs SMA, $2.74 \pm 0.05$; $p=0.04)($ Fig. $5 \mathrm{~J}, K)$. Conversely, MNrescued SMA mice had significantly restored vGlut1 synapse numbers $(3.92 \pm 0.19 ; p \leq$ 0.003 ) and were largely indistinguishable from controls (Fig. $5 J, K$ ). These results demonstrate that the loss of afferent synapses in SMA mice can be rescued by increasing Smn exclusively in MNs.

\section{Hb9-Cre corrects SMA motor neuron hyperexcitability and excess synaptic activity}

To confirm that SMA motor neurons rescued with $\mathrm{Hb}$-Cre were functionally normal, we performed whole-cell patch-clamp measurements on spinal MNs from P4-P5 control, SMA, and MNrescued SMA mice. MNs from all three groups were indistinguishable in appearance, and stable recordings were readily achieved (Fig. 6A-C). There were no significant differences between the control, SMA, or MN-rescued SMA motor neurons in the resting membrane potential, whole-cell capacitance, input resistance, or action potential characteristics (all parameter values are provided in Table 2).

Interestingly, the threshold voltage in SMA motor neurons was significantly lower (more hyperpolarized) relative to controls, and this phenotype was corrected in MN-rescued SMA motor neurons (Table 2). The amplitude of the persistent inward current (PIC) was significantly larger in SMA motor neurons and was restored to con-
B
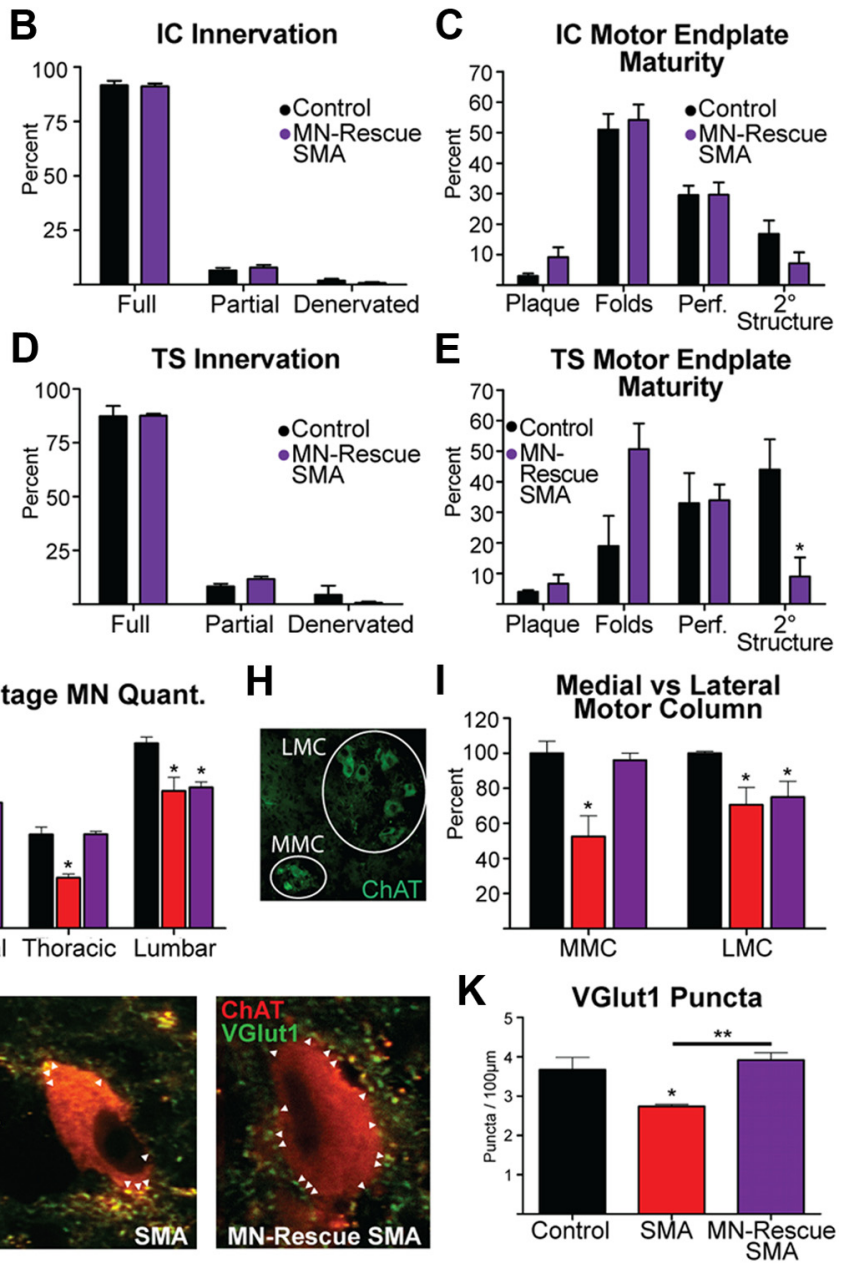

Figure 5. Hb9-Cre rescues motor unit pathology in SMA mice. $\boldsymbol{A}-\boldsymbol{C}$, At end stage, MN-rescued SMA NMJs within the ICS were indistinguishable from controls in innervation status and endplate maturity ( $n=6$ per genotype, $>50$ NMJs per mouse). $\boldsymbol{D}, \boldsymbol{E}$, NMJs within the TS of MN-rescued SMA mice showed no difference in innervation and demonstrated only a variable delay in postsynaptic mice had a significant reduction in the average number of ChAT and Islet-1 double-positive MNs per ventral horn within cervical , thoracic (T8-T11), and lumbar (L2-L5) spinal cord ( $p=0.01, p=0.04$, and $p=0.05$, respectively). In contrast, $M N-$ where $\mathrm{Hb}$ 9-Cre expression is incomplete. Black, Control; red, SMA; purple, MN-rescue SMA. $\boldsymbol{H}, \boldsymbol{I}$, MN-rescued SMA mice did not differ from controls in average number of lumbar MMC neurons and showed a significant $25 \pm 9 \%(p=0.04)$ reduction in LMC neurons. A significant decrease in both MMC $(-47 \pm 12 \% ; p=0.05)$ and LMC $(-29 \pm 10 \% ; p=0.04)$ neurons was observed in severe inducible SMA mice (Student's $t$ test). J, Confocal images of P5 L2-L5 motor neurons. vGlut1 labels the synapses (green), and the . mice had significantly fewer synapses juxtaposed to MNs per $100 \mu \mathrm{m}$ of soma $(2.74 \pm 0.05, p=0.04)$ relative to control littermates Bonferroni's post-test). Scale bars: $50 \mu \mathrm{m}$. Values are shown as mean \pm SEM. ${ }^{*} p \leq 0.05 ;{ }^{* *} p \leq 0.01$.

trol levels by Hb9-Cre. Together, the changed PIC amplitude and threshold voltage parameters would suggest that increased excitability (hyperexcitability) is a property of SMA motor neurons that can be corrected by rescuing Smn levels exclusively within MNs.

Normally, it is not necessary to add blockers of synaptic activity to this preparation since there is minimal spontaneous synaptic activity in the quiescent preparation, though much of the circuitry remains intact. However, there was an unusually high frequency of postsynaptic potentials (PSPs) in SMA motor neurons, as shown in the voltage traces in Figure $6 D-G$. This was quantified as a significant increase in the number of potentials per second in severe inducible SMA mice $(12.4 \pm 5.1 ; p=0.05)$ relative to control littermates $(3.3 \pm 0.3)$. Importantly, $\mathrm{MN}$ rescued SMA motor neurons did not show increased PSPs rela- 
Table 2. Electrophysiological properties of motor neurons

\begin{tabular}{lccc}
\hline & Wild type & SMA & MN-rescued SMA \\
& {$[$ mean \pm SEM $(n)]$} & {$[$ mean \pm SEM $(n)]$} & {$[$ mean \pm SEM $(n)]$} \\
\hline RMP (mV) & $-57 \pm 1(12)$ & $-56 \pm 3(6)$ & $-56 \pm 3(7)$ \\
Capacitance (pF) & $224 \pm 34(12)$ & $176 \pm 38(7)$ & $212 \pm 37(7)$ \\
Input resistance (M $\Omega)$ & $62 \pm 6(12)$ & $75 \pm 25(7)$ & $51 \pm 10(7)$ \\
PIC amplitude (pA) & $-106 \pm 16(12)$ & $-244 \pm 66(7)^{*}$ & $-109 \pm 52(8)^{\dagger}$ \\
AP overshoot (mV) & $30.5 \pm 2(12)$ & $27.7 \pm 5(6)$ & $26.4 \pm 2(7)$ \\
AP duration (ms) & $1.29 \pm 0.1(12)$ & $1.32 \pm 0.02(6)$ & $1.46 \pm 0.02(7)$ \\
AP rate of rise (mV/ms) & $97 \pm 9(12)$ & $115 \pm 17(6)$ & $84 \pm 9(7)$ \\
V threshold (mV) & $-33.9 \pm 1.9(12)$ & $-41.5 \pm 2.5(6)^{*}$ & $-31.1 \pm 2.5(7)^{\dagger}$ \\
I-ON (pA) & $371 \pm 86(12)$ & $246 \pm 122(6)$ & $461 \pm 137(7)$ \\
I-OFF (pA) & $409 \pm 136(12)$ & $445 \pm 90(6)$ & $536 \pm 126(7)$ \\
Slope (Hz/nA) & $37 \pm 8(12)$ & $31 \pm 8(6)$ & $33 \pm 9(7)$ \\
Synaptic potentials (/s) & $3.3 \pm 0.3(12)$ & $12.4 \pm 5.1(5)^{*}$ & $2.5 \pm 0.6(7)^{\dagger}$ \\
\hline
\end{tabular}

Table values are mean \pm SEM $* p \leq 0.05$ relative to control; $\uparrow p \leq 0.05$ relative to SMA, one-way ANOVA with a Bonferroni post hoc analysis. Definitions: RMP, resting membrane potential; capacitance, whole cell capacitance; PIC amplitude, amplitude of the persistent inward current; AP overshoot, overshoot of the action potential (AP) past $0 \mathrm{mV}$; AP duration, duration of the AP at half-peak; AP rate of rise, rate of rise of the action potential; $V$ threshold, threshold of the cell for AP firing; $I-O N$, the amount of current needed to elicit AP firing during a ramp of depolarizing current; $\mathrm{I}-\mathrm{OFF}$, the level of depolarizing current at which firing ceases during the descending current ramp; slope, slope of the frequency — current relationship; synaptic potentials, frequency of post-synaptic potentials in MNs at rest.

tive to control littermates $(2.5 \pm 0.6)$ (Table 2$)$. These results highlight the fact that alterations in motor circuitry are concomitant with alterations in the intrinsic properties of SMA motor neurons, since $\mathrm{Hb}$-Cre abolished the increased frequency of postsynaptic potentials.

\section{MN-rescued SMA mice have autonomic defects}

The degree of improvement observed in motor function, pathology, and electrophysiology makes it unlikely that NMJ dysfunction is the underlying cause of lethality in MN-rescued SMA pups. In recent years, a number of non-neuromuscular defects have been observed in SMA mice that could additively contribute to lethality in the absence of paralysis, one of which is cardiac defects (Bevan et al., 2010; Heier et al., 2010a; Shababi et al., 2010). Since we observed bradyarrhythmia in our severe inducible SMA mice and have previously documented similar findings in delta-7 SMA mice (Heier et al., 2010a), we assessed its presence as a contributing factor to lethality in MN-rescued SMA mutants. Unlike SMA mice without induction, MN-rescued SMA pups did not present with cardiac defects quantifiable by ECG early in life. However, by P9, mutants began to exhibit significant and progressive bradycardia (MN-rescued SMA, $503 \pm 32$ bpm vs control, $688 \pm 9 \mathrm{bpm} ; p=0.001$ ) (Fig. $7 A, B$ ). Similar to what has been reported in delta-7 mice, end-stage MN-rescued SMA mice had signs of terminal heart block that manifested as skipped or dropped beats (Fig. 7B) (Heier et al., 2010a).

We further analyzed the components of ECG, such as the PR interval, QT interval, and QRS interval (Fig. 7C). Severe inducible SMA mice had significantly longer PR, QT, and QRS intervals at all time points examined (P3-P7; $p<0.05)($ Fig. $7 D-F)$. In contrast, MN-rescued SMA mice did not differ from controls early in life, but did exhibit significantly longer PR and QT intervals from P9 to P11 ( $p<0.01$ and $p<0.05$, respectively) (Fig. $7 D, E)$. MN-rescued SMA mice did not display any alterations in QRS interval (Fig. $7 F$ ). These results indicate that the ability of the myocardium to contract in response to ventricular depolarization was unaffected by disease (QRS), while the cardiac nervous system demonstrated delays in electrical conductance (PR and QT).

Previously, we demonstrated reduced sympathetic neuron staining and axon branches in the hearts of delta-7 SMA mice; however, it was unclear whether this was a primary deficit or a secondary complication of muscle weakness (Heier et al., 2010a). To assess the cardiac autonomic innervation pattern in $\mathrm{MN}$ rescued SMA mice, who do not demonstrate significant paralysis, we performed tyrosine hydroxylase (TH) staining on control, SMA, and MN-rescued SMA mice. After standardizing the size of control and mutant hearts digitally using Photoshop, an average of $14 \pm 0.5$ major visible branches was quantified in control mice. In contrast, a significant reduction to $10 \pm 1$ and $11 \pm 1$ visible branches was observed in SMA and MN-rescued SMA mice ( $p=$ 0.02 and $p=0.008$ ), respectively (Fig. $7 G, H)$. Importantly, these defects in autonomic innervation exist in the absence of significant paralysis and/or motor unit pathology. This suggests that they are primary defects that likely combine with other nonneuromuscular defects and additively contribute to the poor health of SMA mice, both in the presence and absence of motor unit dysfunction.

\section{Discussion}

Here we describe a novel mouse model of SMA with the ability to increase Smn dosage to asymptomatic levels after exposure to Cre-recombinase. Our model presents with severe SMA-like symptoms and pathology that are most similar to the severe model described by Monani et al. (2000) (Jax strain 5024). The experiments described in this manuscript demonstrate that $\mathrm{MN}$ rescue with $\mathrm{Hb}$ 9-Cre can significantly improve motor function and motor unit pathology, which are commonly deficient in SMA mice. Furthermore, electrophysiology demonstrates that increasing Smn specifically within MNs is sufficient to correct hyperexcitability in SMA MNs, as well as abolish aberrant synaptic input to MNs.

\section{Involvement of pathology outside the CNS}

Despite a lack of significant paralysis, median survival is only extended $5 \mathrm{~d}$ in MN-rescued SMA mice. Our results, combined with those of Park et al. (2010), indicate that defects external to the MN exasperate the SMA phenotype by compromising the overall health of the mouse, but future experiments are required to definitively confirm this. One potential caveat to this interpretation is that inefficient Cre excision could be the root of lethality in our model and the cause of recovery in the Olig2-Cre SMA mice (Park et al., 2010). While unlikely, such a result would further emphasize the importance of MNs in the SMA phenotype, since a dramatic change in phenotype would be observed despite inefficient recombination. We attribute lethality in MN-rescued SMA mice, in part, to autonomic deficits in cardiac innervation and resulting heart failure. However, the severe phenotype in this model makes it probable that additional, non-neuromuscular factors also contribute to the observed lethality. Interestingly, there is mounting evidence to suggest that other cell types such as hepatocytes, osteoclasts, and myofibers may be affected in SMA mice, although it is unclear whether these defects are primary or secondary (Guettier-Sigrist et al., 2002; Araujo Ade et al., 2009; Shanmugarajan et al., 2009; Bevan et al., 2010; Heier et al., 2010a; Shababi et al., 2010; Wishart et al., 2010; Hua et al., 2011; Mutsaers et al., 2011). Despite the presence of non-neuromuscular phenotypes in severe SMA mice, it remains clear that long-term survival can be achieved with predominantly CNS-specific SMN rescue (Gavrilina et al., 2008; Foust et al., 2010; Passini et al., 2010, 2011; Hua et al., 2011; Osman et al., 2011).

\section{MN pathology supports defects in central spinal circuitry}

Several recent reports indicate that loss of the primary afferents that synapse onto MNs is an early hallmark and potentially significant contributor or mechanistic root of the SMA phenotype 
in mice (Ling et al., 2010; Park et al., 2010; Mentis et al., 2011). As has been noted in other SMA mouse models, the level of MN electrophysiological dysfunction quantified in our model is not sufficient to explain the significant reduction in motor function that exists (Zhang et al., 2010; Mentis et al., 2011). Given the high safety factor for neuromuscular transmission, the synaptic transmission defects that have been described in delta-7 SMA mice are also unlikely, on their own, to account for the observed phenotype (Kong et al., 2009; Ling et al., 2010; Ruiz et al., 2010). Hence, in our model the presence of hyperexcitable MNs, which experience an increased frequency of postsynaptic events and a loss of glutamatergic synapses, supports the conclusion that defects in spinal circuitry above the NMJ, such as sensory-motor synapses, play a significant role in driving the progression of a SMA-like disease in mice and potentially human SMA patients.

Here, we show an increased frequency of postsynaptic events in SMA MNs, whereas a previous study demonstrated decreased afferent input (Mentis et al., 2011). On the surface, these results appear to conflict; however, they are not mutually exclusive. Since synaptic formation and maintenance is altered between proprioceptive, vGlut1expressing neurons and MNs, the formation and maintenance of synaptic contacts with other neurons, for example, local spinal interneurons that do not express vGlut1, could be altered as well. Therefore, deficits in afferent input are potentially part of the same altered circuitry that is responsible for the increased spontaneous synaptic activity.

In addition to $\mathrm{Hb} 9$-positive $\mathrm{MNs}$, another group of neurons could be involved in the rescued phenotype: the $\mathrm{Hb} 9$ interneurons. This small population of glutamatergic interneurons ( $\sim 40$ per segment) is present in limited thoracic and lumbar spinal cord segments, T13-L3 (Hinckley et al., 2005; Wilson et al., 2005; Kwan et al., 2009). They receive monosynaptic input from sensory afferents (Hinckley et al., 2010) and have sparse synaptic contacts with MNs (Hinckley et al., 2005; Wilson et al., 2005). Since Hb9 interneurons are also rescued, it could be argued that loss of Smn protein renders them hyperexcitable, and their subsequent rescue explains the absence of aberrant synaptic activity. However, this is highly improbable, since contacts between Hb9 interneurons and MNs are rare (Wilson et al., 2005), and based on their low levels of activity during activation of the locomotor network, the possibility that these interneurons drive another population of premotor interneurons in quiescent cord appears somewhat remote (Kwan et al., 2009).

\section{Pathology of MNs}

Some of the findings here are not identical to those of previous studies. In this SMA model, we did not observe changes in input resistance or action potential height, as was reported in Mentis et al. (2011). This may be due to the different SMA models or the preparations used (whole isolated spinal cord vs spinal cord slice). However, our observations are similar to previous studies in that the threshold voltage of SMA MNs is more hyperpolarized, which would allow them to fire with less depolarizing input (Zhang et al., 2010; Mentis et al., 2011). Increased excitability, including an increased persistent inward current, has been observed in other conditions of spinal MN dysfunction, such as spinal cord injury and MN disease (Li and Bennett, 2003; Kuo et al., 2005; Harvey et al., 2006; Meehan et al., 2010; Quinlan et al., 2011). This might indicate that MN excitability is a common thread in SMA and, more broadly, in MN pathology.

\section{Defects in sensory-motor synapses are specific to MNs}

Aberrant synaptic activity in SMA can be explained by altered synapse development and maintenance. Since synaptic integrity requires faithful and reciprocal presynaptic and postsynaptic signaling, the loss of sensory-MN interaction could be due to a failure of primary afferents to deliver appropriate neurotransmitters across the synapse. Alternatively, the inability of the postsynaptic MN to maintain normal levels of 


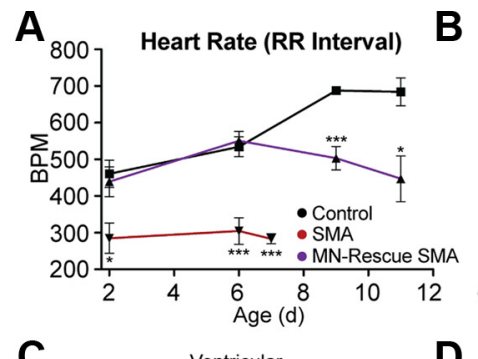

B
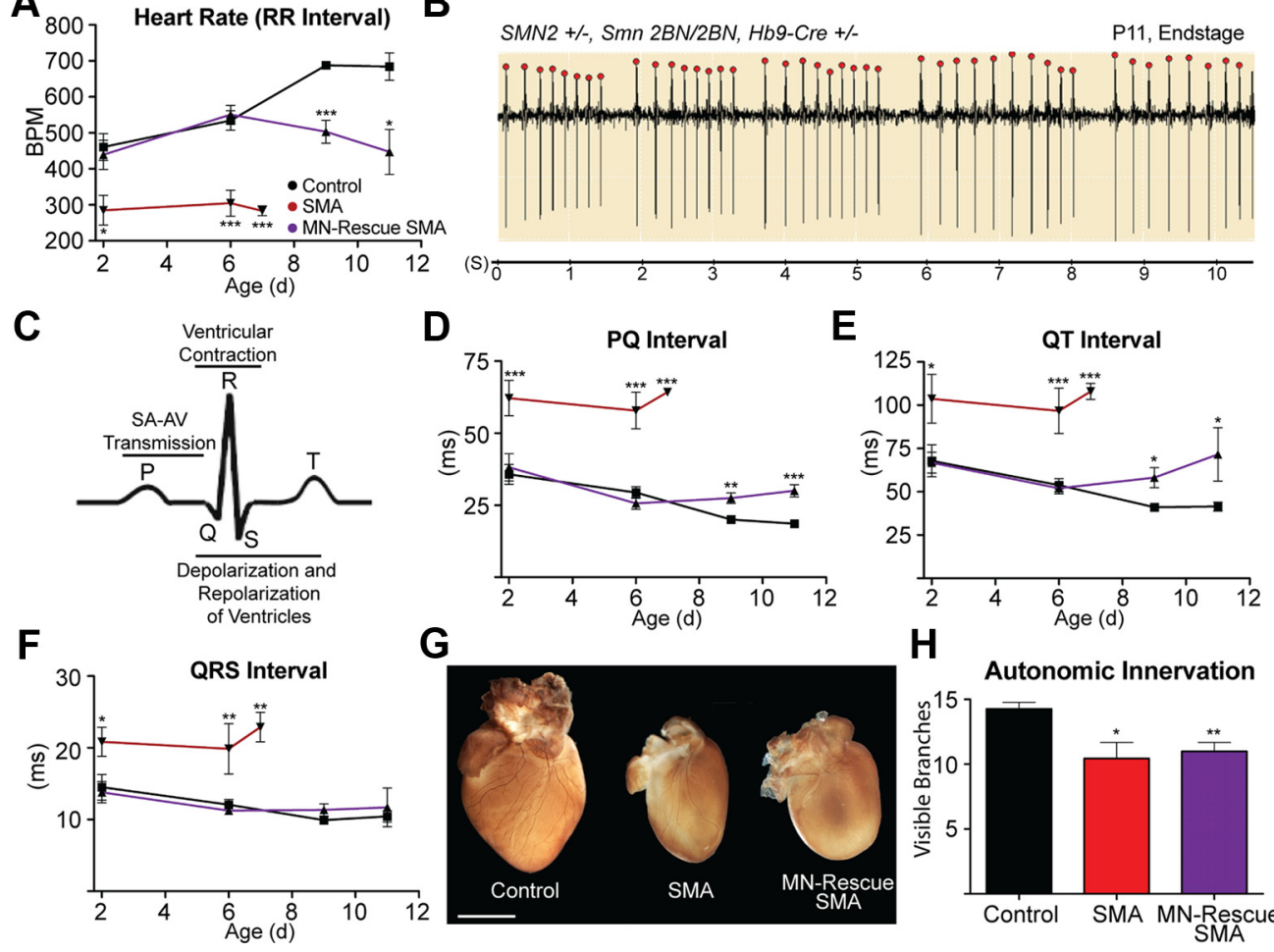

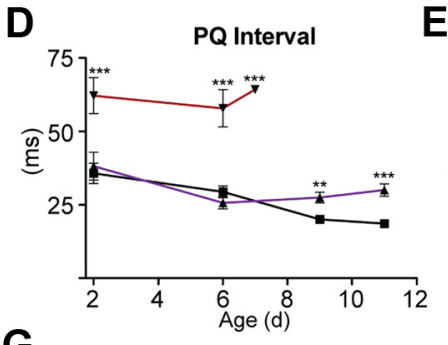

G

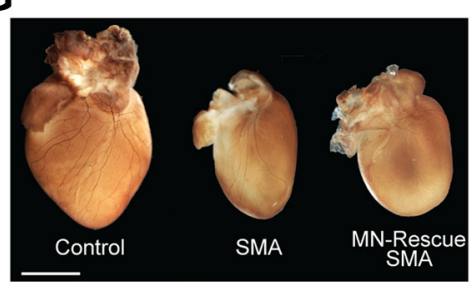

E

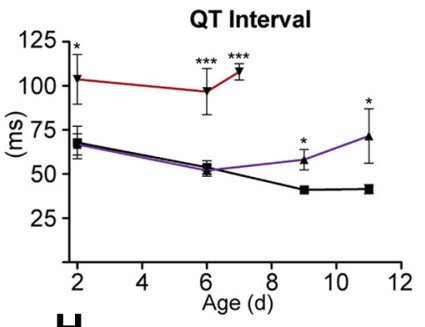

H Autonomic Innervation

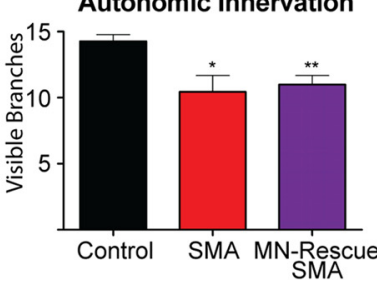

Figure 7. MN-rescued SMA mice have deficits in autonomic control of the heart. $A, B$, The heart rate of MN-rescued SMA mice $(n=7)$ did not differ from controls ( $n=14)$ early in life. However, at $P 9, M N$-rescued SMA mice became significantly bradycardic $(p \leq 0.001)$ and began to show hallmark signs of terminal heart block, which manifested as dropped beats and prolonged PR interval (SMA, $n=6$; Student's $t$ test). C, Schematic of the relevant components of ECG. SA, sinoatrial node; AV, atrioventricular node. D, E, MN-rescued SMA mice demonstrated deficits in aspects of ECG that are attributable to problems in sympathetic innervation of the heart, such as SA-AV signal transmission (P9-P11; $p \leq 0.01$ ) and duration from depolarization to repolarization of the ventricles (P9-P11; $p \leq 0.05$ ) (Student's t test). $\boldsymbol{F}$, MN-rescued SMA mice did not differ from controls in duration of the QRS complex, suggesting that the ability of the myocardium to contract once depolarized was intact. $\mathbf{G}, \boldsymbol{H}$, Sympathetic innervation of the heart was visualized with tyrosine hydroxylase staining at P5. A significant loss in major visible branches was quantified in both SMA ( $n=3$ ) and MN-rescued SMA mouse hearts $(n=4)$ relative to controls $(n=4)$, suggesting that this phenotype is independent of motor unit dysfunction (Student's $t$ test). Values are shown as mean \pm SEM. Scale bar, $1 \mathrm{~mm} .{ }^{*} p \leq 0.05 ;{ }^{* *} p \leq 0.01 ; * * * 0 \leq 0.001$.

excitability could result in the loss of primary afferent synapses, while other synaptic contacts are upregulated. Results from this study would argue that the latter is the mechanism of afferent synapse loss in SMA, since our MN-rescued SMA mice, who express only asymptomatic levels of Smn in MNs, do not show a loss in vGlutl bouton number or evidence of altered synaptic inputs. This finding is in agreement with the previous observation that sensory-motor synapses are lost in mice that have normal Smn dosage in all cells except MNs and oligodendrocytes (Park et al., 2010).

The existence of non-neuromuscular contributions to lethality makes it challenging to determine whether, with prolonged survival, aberrant synaptic activity in $\mathrm{Hb} 9$-Cre-rescued SMA motor neurons would develop; however, dissecting this will require milder inducible models of SMA than the one described here. Together, these findings suggest that the role of the postsynaptic cell should not be underestimated in maintenance of afferent synapses.

\section{Conclusions}

Collectively, our results and those of others indicate that deficits in the central circuit play a significant role in SMA disease progression and paralysis in severe SMA mice and potentially human SMA patients (Ling et al., 2010; Park et al., 2010; Mentis et al., 2011). Moreover, our results support the idea that loss of sensorymotor synapses is a consequence, and not a cause, of MN dysfunction. Finally, this work demonstrates that neuromuscular dysfunction in SMA mice is mechanistically due to deficits within MNs. These defects are enhanced by the presence of additional primary or secondary defects, all of which act additively to comprise the general health of the mouse. As such, this work does not rule out the potentially significant benefits of restoring Smn within the other components of the motor unit, such as skeletal muscle and/or Schwann cells, which may play important roles in defining disease severity. Future work determining how many rescued MNs are required to affect a phenotypic benefit will have important implications in developing effective therapies to treat SMA patients.

\section{References}

Araujo Ade Q, Araujo M, Swoboda KJ (2009) Vascular perfusion abnormalities in infants with spinal muscular atrophy. J Pediatr 155:292-294.

Arber S, Han B, Mendelsohn M, Smith M, Jessell TM, Sockanathan S (1999) Requirement for the homeobox gene $\mathrm{Hb} 9$ in the consolidation of motor neuron identity. Neuron 23:659-674.

Bevan AK, Hutchinson KR, Foust KD, Braun L, McGovern VL, Schmelzer L, Ward JG, Petruska JC, Lucchesi PA, Burghes AH, Kaspar BK (2010) Early heart failure in the SMNDelta7 model of spinal muscular atrophy and correction by postnatal scAAV9-SMN delivery. Hum Mol Genet 19:3895-3905.

Boon KL, Xiao S, McWhorter ML, Donn T, Wolf-Saxon E, Bohnsack MT, Moens CB, Beattie CE (2009) Zebrafish survival motor neuron mutants exhibit presynaptic neuromuscular junction defects. Hum Mol Genet 18:3615-3625.

Briese M, Esmaeili B, Fraboulet S, Burt EC, Christodoulou S, Towers PR, Davies KE, Sattelle DB (2009) Deletion of smn-1, the Caenorhabditis 
elegans ortholog of the spinal muscular atrophy gene, results in locomotor dysfunction and reduced lifespan. Hum Mol Genet 18:97-104.

Chang HC, Dimlich DN, Yokokura T, Mukherjee A, Kankel MW, Sen A, Sridhar V, Fulga TA, Hart AC, Van Vactor D, Artavanis-Tsakonas S (2008) Modeling spinal muscular atrophy in Drosophila. PLoS One 3:e3209.

Coovert DD, Le TT, McAndrew PE, Strasswimmer J, Crawford TO, Mendell JR, Coulson SE, Androphy EJ, Prior TW, Burghes AH (1997) The survival motor neuron protein in spinal muscular atrophy. Hum Mol Genet 6:1205-1214.

Crawford TO, Pardo CA (1996) The neurobiology of childhood spinal muscular atrophy. Neurobiol Dis 3:97-110.

DiDonato CJ, Parks RJ, Kothary R (2003) Development of a gene therapy strategy for the restoration of survival motor neuron protein expression: implications for spinal muscular atrophy therapy. Hum Gene Ther 14:179-188.

Foust KD, Wang X, McGovern VL, Braun L, Bevan AK, Haidet AM, Le TT, Morales PR, Rich MM, Burghes AH, Kaspar BK (2010) Rescue of the spinal muscular atrophy phenotype in a mouse model by early postnatal delivery of SMN. Nat Biotechnol 28:271-274.

Gavrilina TO, McGovern VL, Workman E, Crawford TO, Gogliotti RG, DiDonato CJ, Monani UR, Morris GE, Burghes AH (2008) Neuronal SMN expression corrects spinal muscular atrophy in severe SMA mice while muscle-specific SMN expression has no phenotypic effect. Hum Mol Genet 17:1063-1075.

Guettier-Sigrist S, Hugel B, Coupin G, Freyssinet JM, Poindron P, Warter JM (2002) Possible pathogenic role of muscle cell dysfunction in motor neuron death in spinal muscular atrophy. Muscle Nerve 25:700-708.

Hammond SM, Gogliotti RG, Rao V, Beauvais A, Kothary R, DiDonato CJ (2010) Mouse survival motor neuron alleles that mimic SMN2 splicing and are inducible rescue embryonic lethality early in development but not late. PLoS One 5:e15887.

Harvey PJ, Li Y, Li X, Bennett DJ (2006) Persistent sodium currents and repetitive firing in motoneurons of the sacrocaudal spinal cord of adult rats. J Neurophysiol 96:1141-1157.

Heier CR, Satta R, Lutz C, DiDonato CJ (2010a) Arrhythmia and cardiac defects are a feature of spinal muscular atrophy model mice. Hum Mol Genet 19:3906-3918.

Heier CR, Hampton TG, Wang D, Didonato CJ (2010b) Development of electrocardiogram intervals during growth of $\mathrm{FVB} / \mathrm{N}$ neonate mice. BMC Physiol 10:16.

Hinckley CA, Hartley R, Wu L, Todd A, Ziskind-Conhaim L (2005) Locomotor-like rhythms in a genetically distinct cluster of interneurons in the mammalian spinal cord. J Neurophysiol 93:1439-1449.

Hinckley CA, Wiesner EP, Mentis GZ, Titus DJ, Ziskind-Conhaim L (2010) Sensory modulation of locomotor-like membrane oscillations in Hb9expressing interneurons. J Neurophysiol 103:3407-3423.

Hsieh-Li HM, Chang JG, Jong YJ, Wu MH, Wang NM, Tsai CH, Li H (2000) A mouse model for spinal muscular atrophy. Nat Genet 24:66-70.

Hua Y, Sahashi K, Rigo F, Hung G, Horev G, Bennett CF, Krainer AR (2011) Peripheral SMN restoration is essential for long-term rescue of a severe spinal muscular atrophy mouse model. Nature 478:123-126.

Kong L, Wang X, Choe DW, Polley M, Burnett BG, Bosch-Marce M, Griffin JW, Rich MM, Sumner CJ (2009) Impaired synaptic vesicle release and immaturity of neuromuscular junctions in spinal muscular atrophy mice. J Neurosci 29:842-851.

Kramer ER, Knott L, Su F, Dessaud E, Krull CE, Helmbacher F, Klein R (2006) Cooperation between GDNF/Ret and ephrinA/EphA4 signals for motor-axon pathway selection in the limb. Neuron 50:35-47.

Kuo JJ, Siddique T, Fu R, Heckman CJ (2005) Increased persistent Na+ current and its effect on excitability in motoneurones cultured from mutant SOD1 mice. J Physiol 563:843-854.

Kwan AC, Dietz SB, Webb WW, Harris-Warrick RM (2009) Activity of Hb9 interneurons during fictive locomotion in mouse spinal cord. J Neurosci 29:11601-11613.

Le TT, Pham LT, Butchbach ME, Zhang HL, Monani UR, Coovert DD, Gavrilina TO, Xing L, Bassell GJ, Burghes AH (2005) SMNDelta7, the major product of the centromeric survival motor neuron (SMN2) gene, extends survival in mice with spinal muscular atrophy and associates with fulllength SMN. Hum Mol Genet 14:845-857.
Le TT, McGovern VL, Alwine IE, Wang X, Massoni-Laporte A, Rich MM, Burghes AH (2011) Temporal requirement for high SMN expression in SMA mice. Hum Mol Genet 20:3578-3591.

Lefebvre S, Bürglen L, Reboullet S, Clermont O, Burlet P, Viollet L, Benichou B, Cruaud C, Millasseau P, Zeviani M, et al (1995) Identification and characterization of a spinal muscular atrophy-determining gene. Cell 80:155-165.

Lefebvre S, Burlet P, Liu Q, Bertrandy S, Clermont O, Munnich A, Dreyfuss G, Melki J (1997) Correlation between severity and SMN protein level in spinal muscular atrophy. Nat Genet 16:265-269.

Li Y, Bennett DJ (2003) Persistent sodium and calcium currents cause plateau potentials in motoneurons of chronic spinal rats. J Neurophysiol 90:857-869.

Ling KK, Lin MY, Zingg B, Feng Z, Ko CP (2010) Synaptic defects in the spinal and neuromuscular circuitry in a mouse model of spinal muscular atrophy. PLoS One 5:e15457.

McGovern VL, Gavrilina TO, Beattie CE, Burghes AH (2008) Embryonic motor axon development in the severe SMA mouse. Hum Mol Genet 17:2900-2909.

Meehan CF, Moldovan M, Marklund SL, Graffmo KS, Nielsen JB, Hultborn $\mathrm{H}$ (2010) Intrinsic properties of lumbar motor neurones in the adult G127insTGGG superoxide dismutase-1 mutant mouse in vivo: evidence for increased persistent inward currents. Acta Physiol 200:361-376.

Mentis GZ, Blivis D, Liu W, Drobac E, Crowder ME, Kong L, Alvarez FJ, Sumner CJ, O’Donovan MJ (2011) Early functional impairment of sensory-motor connectivity in a mouse model of spinal muscular atrophy. Neuron 69:453-467.

Monani UR, Sendtner M, Coovert DD, Parsons DW, Andreassi C, Le TT, Jablonka S, Schrank B, Rossol W, Prior TW, Morris GE, Burghes AH (2000) The human centromeric survival motor neuron gene (SMN2) rescues embryonic lethality in $\operatorname{Smn}(-/-)$ mice and results in a mouse with spinal muscular atrophy. Hum Mol Genet 9:333-339.

Murray LM, Comley LH, Thomson D, Parkinson N, Talbot K, Gillingwater TH (2008) Selective vulnerability of motor neurons and dissociation of pre- and post-synaptic pathology at the neuromuscular junction in mouse models of spinal muscular atrophy. Hum Mol Genet 17:949-962.

Mutsaers CA, Wishart TM, Lamont DJ, Riessland M, Schreml J, Comley LH, Murray LM, Parson SH, Lochmüller H, Wirth B, Talbot K, Gillingwater TH (2011) Reversible molecular pathology of skeletal muscle in spinal muscular atrophy. Hum Mol Genet 20:4334-4344.

Novak A, Guo C, Yang W, Nagy A, Lobe CG (2000) Z/EG, a double reporter mouse line that expresses enhanced green fluorescent protein upon Cremediated excision. Genesis 28:147-155.

Osman EY, Yen PF, Lorson CL (2011) Bifunctional RNAs targeting the intronic splicing silencer $\mathrm{N} 1$ increase SMN levels and reduce disease severity in an animal model of spinal muscular atrophy. Mol Ther 20:119-126.

Park GH, Maeno-Hikichi Y, Awano T, Landmesser LT, Monani UR (2010) Reduced survival of motor neuron (SMN) protein in motor neuronal progenitors functions cell autonomously to cause spinal muscular atrophy in model mice expressing the human centromeric (SMN2) gene. J Neurosci 30:12005-12019.

Passini MA, Bu J, Roskelley EM, Richards AM, Sardi SP, O’Riordan CR, Klinger KW, Shihabuddin LS, Cheng SH (2010) CNS-targeted gene therapy improves survival and motor function in a mouse model of spinal muscular atrophy. J Clin Invest 120:1253-1264.

Passini MA, Bu J, Richards AM, Kinnecom C, Sardi SP, Stanek LM, Hua Y, Rigo F, Matson J, Hung G, Kaye EM, Shihabuddin LS, Krainer AR, Bennett CF, Cheng SH (2011) Antisense oligonucleotides delivered to the mouse CNS ameliorate symptoms of severe spinal muscular atrophy. Sci Transl Med 3:72ra18

Pellizzoni L, Kataoka N, Charroux B, Dreyfuss G (1998) A novel function for SMN, the spinal muscular atrophy disease gene product, in premRNA splicing. Cell 95:615-624.

Quinlan KA, Schuster JE, Fu R, Siddique T, Heckman CJ (2011) Altered postnatal maturation of electrical properties in spinal motoneurons in a mouse model of amyotrophic lateral sclerosis. J Physiol 589:2245-2260.

Ruiz R, Casañas JJ, Torres-Benito L, Cano R, Tabares L (2010) Altered intracellular Ca2 + homeostasis in nerve terminals of severe spinal muscular atrophy mice. J Neurosci 30:849-857.

Schrank B, Götz R, Gunnersen JM, Ure JM, Toyka KV, Smith AG, Sendtner M 
(1997) Inactivation of the survival motor neuron gene, a candidate gene for human spinal muscular atrophy, leads to massive cell death in early mouse embryos. Proc Natl Acad Sci U S A 94:9920-9925.

Shababi M, Habibi J, Yang HT, Vale SM, Sewell WA, Lorson CL (2010) Cardiac defects contribute to the pathology of spinal muscular atrophy models. Hum Mol Genet 19:4059-4071.

Shanmugarajan S, Tsuruga E, Swoboda KJ, Maria BL, Ries WL, Reddy SV (2009) Bone loss in survival motor neuron $(\operatorname{Smn}(-/-)$ SMN2) genetic mouse model of spinal muscular atrophy. J Pathol 219:52-60.

Tremblay P, Bouzamondo-Bernstein E, Heinrich C, Prusiner SB, DeArmond SJ (2007) Developmental expression of PrP in the post-implantation embryo. Brain Res 1139:60-67.
Wilson JM, Hartley R, Maxwell DJ, Todd AJ, Lieberam I, Kaltschmidt JA, Yoshida Y, Jessell TM, Brownstone RM (2005) Conditional rhythmicity of ventral spinal interneurons defined by expression of the $\mathrm{Hb} 9$ homeodomain protein. J Neurosci 25:5710-5719.

Wishart TM, Huang JP, Murray LM, Lamont DJ, Mutsaers CA, Ross J, Geldsetzer P, Ansorge O, Talbot K, Parson SH, Gillingwater TH (2010) SMN deficiency disrupts brain development in a mouse model of severe spinal muscular atrophy. Hum Mol Genet 19:4216-4228.

Zhang H, Robinson N, Wu C, Wang W, Harrington MA (2010) Electrophysiological properties of motor neurons in a mouse model of severe spinal muscular atrophy: in vitro versus in vivo development. PLoS One 5:e11696. 